\title{
INTRODUCTION OF THE ELECTROLYSIS OF BRINE FOR THE SUPPLY OF DRINKING WATER TO A MARGINALIZED POPULATION
}

\author{
Nelson Barranco ${ }^{1 *}$ \\ ${ }^{*}$ CEI-LABAICA, Technical University of Panama,nelson.barraco@utp.ac.pa
}

Corresponding Author: -

Email: nelson.barraco@utp.ac.pa

\begin{abstract}
: -
In our country the Institute of aqueducts and sewage systems, is responsible for providing all the Panamanian population drinking water. However, the communities with less 1,500 inhabitants are handled by the Ministry of health, by the socalled rural aqueducts; which are managed by the communities themselves. Most of these rural aqueducts operate with many deficiencies. Thus, the availability of drinking water to rural populations is very insecure. Preceding this reason exposed, and analyzing different methods of disinfection for drinking water especially for rural areas, we select the electrolysis of brine, as a good alternative; already this method as well as low cost of maintenance and operation, requires raw salt, or sea water; what is available anywhere in one way or another to produce hypochlorite of sodium, generated by electrolysis.

Through the introduction of the process of electrolysis of brine, which operated using renewable energy sources (photovoltaic), being this self-sustaining, especially for hard-to-reach places. Generated potable water for consumption, and food preparation. The water obtained complies with the regulation technical DGNT-COPANIT 23-395-99, for drinking water.

We empower the community with this project, to generate themselves the disinfectant of sodium hypochlorite, resulting this in a social innovation project.

The project counted with the collaboration of the technical staff of the laboratory of Industrial analysis and environmental sciences of the Experimental Center of engineering at the Technological University of Panama. And it was endorsed and financially supported by the National Secretariat for science, technology and innovation.
\end{abstract}

Keywords: - Electrolysis of brine, sodium hypochlorite, photovoltaics, drinking water, marginalized population, disinfection, rural population, line base, self-sustaining, rural aqueducts.

\section{(c) $(\$)$}




\section{INTRODUCTION}

In our country the Institute of aqueducts and sewers (IDAAN) [1] is responsible for providing all the Panamanian population drinking water. More however, IDAAN only serves the towns of 1,500 inhabitants and more. Communities with less population are handled by the Ministry of health (MINSA) by the so-called rural aqueducts; which are managed by the communities themselves. Most of these rural aqueducts operate with many shortcomings, either by lack of medium disinfectant or lack of maintenance of pumps or turbines, which work with electric current, whose delivery depends on many factors.

Thus, the availability of drinking water to rural populations is very insecure [2].

Even more so since the Organization of United Nations (UN) (2010) stipulated as an inalienable human right to have access to safe drinking water [3], this obliges Governments to seek concrete and effective solutions to the problem, many times for marginalized populations with access to drinking water, required a radical change in technology to apply, which unfortunately often seeks to reduce costs of production and distribution of the vital liquid, putting people's health at risk.

Preceding the reasons stated, and analyzing the different systems of disinfection for drinking water especially for rural areas, we select the electrolysis of brine [4], as a good alternative; already this method as well as low cost of maintenance and operation, requires as raw material: raw salt, or sea water; What is available anywhere in one way or another. As a source of energy for electrolysis was chosen a photovoltaic cell, and thus achieve absolute independence of the process.

\section{Benefits and main beneficiaries}

Through the introduction of the process of electrolysis of brine, you can reduce the cost of electricity in the water purification, since it operates using renewable sources of energy, photovoltaics. On the other hand, have independence from external supplies, due to the use of chemicals generated in site, sodium hypochlorite, through the electrolysis of brine (salt solution); in other words, almost no costs, only the salt.

The main beneficiaries are 540 inhabitants (60\% among children and young people) of the community Ipetí Emberá, Torti, district of Chepo, Panama East, consisting of 78 houses approximately [5] [6], as also its visitors, eco tourism activities of the place.

\section{Expected impact}

The population benefited through the project reached a better quality of life since, having access to safe drinking water improved their health conditions and I decreased the incidence of diarrhea diseases, which generated greater intellectual and productive, solving part of the socio-economic problems.

The socio-economic impact by implementing this project can not be measured within the same duration. However, is expected to make an evaluation post-project, a year after the completion of this project to evaluate the impact on the community. The impact of this project will be reflected in the following points:

Quality of the water produced by the method developed with the project compared to other similar technologies.

People trained and sensitized about the use and consumption of drinking water produced by this project in the community of Ipetí and in other neighboring communities that participated.

$\square$ Level of improvement of the health of the community of Ipetí Emberá for use or consumption of the water produced under the method of electrolysis of brine with the technology that runs with this project, post-implementation launched project.

Decrease in the incidence of diarrhea diseases in the community.

Improvement of the indices of poverty of the community benefit.

$\mathrm{CO} 2$ reduction by the use of new renewable technology based on photo solar cell.

\section{General and specific goal achieved}

- Introduced an alternate system for potable water access in the Ipetí Emberá community, contributing to Social innovation in Panama. Executed the following activities successfully:

- Awareness of the benefits obtained by drinking disinfected water.

- Fit within the process of purification of brine electrolysis disinfection.

- Providing clean, safe water to the community of Ipetí Emberá.

- Train the population with the management and operation of the electrolysis of brine and the handling of the photovoltaic cell.

\section{Methodology, materials and methods \\ Awareness, characterization of source water and Diagnostics}

The population of the community of Ipetí Emberá was in conditions of extreme poverty and has benefited from the construction, installation and testing of a plant prototype for the supply of drinking water through the method of electrolysis of brine. This population is supplied with Ipetí river water to drink and meet all its domestic, productive and recreational activities.

From the start implemented awareness-raising lectures and group dynamics (initiation, social, health, economic), children and young people of 35 participants per school age group, more a group of women housewife (20 in total); each group will have a four-hour session. The participants were selected from a simple random sample of 78 homes in the community. This workshop was taught by Lic. Pablo Navarro of the University of Panama sociologist and a student of master of the Faculty of mechanical engineering of the UTP, Lic. Jorge Jaén. 
The source of water for this community is, was and will be the Ipetí River, when the supply of the rural aqueduct is missing, the population uses water for consumption Therefore, it was marked at the beginning of this project, in its biological properties and physical chemical through the taking of samples and the laboratory analysis [9] of Industrial analysis and environmental sciences (LABAICA) - Experimental Center of Engineering (CEI) of the technological University of Panama (UTP). Obtaining a water quality index (ICA) 80 [7], this value is still acceptable, but requires previous treatment and disinfection to be consumed.

After making several arrangements to the hydraulic infrastructure (storage, network distribution and outlet tanks) of the rural aqueduct and adapt and incorporate the electrolysis of brine process, including the installation of solar panels and devices of regulation and control for the electric power supply; it was to train the staff in the management, operation and maintenance. Operation manuals were developed as administrative forms and maintenance and control of the power plant of sodium hypochlorite solution for disinfection of water in the drinking water storage tank.

The results of analyses of drinking water complied with the regulation technical DGNT- COPANIT 23-395-99 [8], after added the disinfectant of sodium hypochlorite, generated by the process of electrolysis of brine.

$$
2 \mathrm{NaCl}+3 \mathrm{H}_{2} \mathrm{O} \stackrel{\mathrm{e}^{-}}{\rightarrow} \mathrm{NaClO}+\mathrm{HOCl}+\mathrm{NaOH}+2 \mathrm{H}_{2}
$$

\section{Conclusions and recommendations}

As a final result, we can conclude, that managed to introduce the process of electrolysis of brine, for disinfection of drinking water, in the community of Ipetí Emberá, with great success. It was a rewarding experience for the whole team, check the results after six years of the process, that this is sustainable in the medium and long term, and who mainly managed to empower the community of the importance of disinfecting drinking water. Resulting this project as a model of Social innovation.

\section{Evaluation of impacts produced by the implementation of the system applied in the community.}

For this stage, it will be necessary to update the line base with information from new health statistics from the community of Ipetí Emberá post-implementation up plant to evaluate the changes produced by the consumption of the water produced with this.

Diagnose and assess the final impact on the community on the use of technology and visitors tourists on the consumption of water produced with the new technology, through surveys.

With the intervention of government institutions is expected to link to the project to keep both specialists and community partnerships for the achievement of the objectives of the project, as well as to evaluate later according to the results of the impact of technology in the community so that they can replicate in other communities to make changes of paradigms in populations that have equal problems in the country.

They were unveiled the results of the implementation of the system through publications and demonstrations to other communities in the region with the same problem, so evaluate the possibility of reproduction; as well as officials and authorities of government institutions that have responsibility for the development of technologies for the improvement of the quality of life of the population.

For its part the Technological University of Panama was responsible for making presentations of the project in its seminars and conferences.

\section{Thanks}

We express our gratitude to the National Secretariat of science, technology and innovation (SENACYT) for having financed this project, also to the staff of the laboratory of Industrial analysis and environmental sciences (LABAICA) of the Experimental Center of Engineering (CEI) of the Technological University of Panama (UTP), by carrying out all the transport and personal cost; and especially to Ipetí Emberá community, for their disposal.

\section{Bibliographic references}

[1].Institute of sewerage and aqueducts national (IDAAN). Statistical Bulletin 2000-2002. Panama

[2].Jorquera; m., Valencia; g., Eguchi, m., Katayose; m. and Riquelme; C. (2002.). Disinfection of seawater for hatchery aquaculture systems using electrolytic water treatment. Aquaculturev. 207, p. 213-224.

[3].Organization of the United Nations. (2010). resolution on the human right to water and sanitation. A/64/L.63/Rev. Accessed 26-8-2010. Address: http://www.politicaspublicas.net/panel/agua/dhagua/667-onu-2010-resolucionagua.html

[4].Equipment \& systems. Engineering, Inc. Aquachlor Installation, operation and Maintenance manual

[5].General Comptroller of the Republic. Panama in figures. Census 2001.

[6].World Health Organization (WHO/PAHO). Ideas and perceptions of indigenous people of Panama communities in relation to the quality of water and sanitation.

[7].Index of water quality (ICA), www.water-research.net/watrqualiindex/NSF.

[8].DGNT-COPANIT 23-395-99 technical regulation [9.] Standard methods, APHA-AWWA-WEF-2012 